\title{
Oil Price Fluctuations and Their Impact on Stock Market Returns in Jordan: Evidence from an Asymmetric Cointegration Analysis
}

\author{
Buthaina M. A. Muhtaseb ${ }^{1} \&$ Ghazi Al-Assaf ${ }^{1}$ \\ ${ }^{1}$ Business Economics Department, School of Business, The University of Jordan, Jordan \\ Correspondence: Ghazi Al-Assaf, Assistant Professor of Economics, Business Economics Department, School of \\ Business, The University of Jordan, Jordan.
}

Received: November 20, 2016

Accepted: January 10, $2017 \quad$ Online Published: January 22, 2017

doi:10.5430/ijfr.v8n1p172

URL: http://dx.doi.org/10.5430/ijfr.v8n1p172

\begin{abstract}
Abstact
This paper examines whether Amman stock market returns responds asymmetrically to oil price fluctuations for the quarterly period 2000-2015 by applying asymmetric cointegration. Using both TAR and MTAR specification of Enders and Siklos's (2001) models, and based on the asymmetric ECM, the results provide evidence that stock returns react to oil price variations in an asymmetric manner. In particular, rising oil prices has a larger impact on stock returns; this implies that increases in oil prices have a significant effect on the behavior of stock market in Jordan. The significant relationship between oil prices and stock returns strengthen their predictability power, so that appropriate strategies may be built on the basis of expected increases or decreases in oil prices.
\end{abstract}

Keywords: oil prices, stock market returns, asymmetric cointegration, Jordan

\section{Introduction}

Oil is considered the world's dominant fuel, and its global market is the most important of the world energy markets (BP Statistical Review of the World Energy, 2016). Its prices have shown great instability in recent times, caused by economic, financial and geopolitical factors. The variations in its prices have a great impact on the overall economy, inflation, the exchange rate, corporate earnings, and other economic variables due to its extensive use as a crucial input in the production process, and as a final consumption good. The tremendous effects of oil price shocks, particularly in certain economies, have stimulated researches to explore the linkage between oil price changes and macroeconomic variables. Scholars, however, have become specifically interested in investigating the relationship between oil price variations and the stock market returns after the latest world economic and financial crisis.

Recent research does not focus only on examining the influence of the changes in oil price level (mean price in a given period), but also the effects of price volatility (standard deviation in a given period). The asymmetry nature of oil price effects on stock returns has also attracted the attention of more and more researchers.

It should be noted that the impact of oil price variations differ from country to another, depending on several factors such as the country's situation as an oil importing or exporting country. Jordan is a net-oil importing country, which depends heavily on oil, and is largely exposed to the developments in the crude oil market. Understanding the nature of the relation between oil price variations and stock returns, in addition to its policy implications is of vital importance for Jordanian policy makers and investors.

Accordingly, the goal of the current paper is to add to the relatively scarce existing literature on developing and emerging countries, specifically that on Jordan's case. To achieve this, we investigate the relationship between oil prices and Amman stock market returns, using quarterly data over the period 2000-2015. Furthermore, the potential asymmetric cointegration relationship between the variables is examined by extending the traditional cointegration analysis employing Enders and Siklos's (2001) TAR and MTAR models along with asymmetric error correction model.

The contribution of the study is not only to conduct a primary investigation of the connection between oil price and stock returns, but also to explore another aspect of this relation, namely; the asymmetric feature and effect of oil price changes. 
The remainder of this paper is structured as follows. Section 2 reviews the main theoretical and empirical literature. In Section 3, the background of the main methodology is discussed. The main empirical results are presented in Section 4. Section 5 concludes.

\section{Review of the Literature}

\subsection{Theoretical Background}

The link between oil prices and stock returns can be explored by explaining the channels through which the changes in oil price can affect real stock market returns. In theory, there are several transmission mechanisms that clarify this relation. According to the financial economic science, there are two main channels. First, based on a microeconomic perspective, a logical way is the channel of expected cash flow. Oil is an important input in the production process; therefore, higher production costs due to higher oil prices will adversely affect margins, cash flows and hence stock prices. Second, according to the macroeconomic view, oil prices may impact stock returns via the discount rate. An oil price increase often results in inflationary pressures. The central bank may raise the interest rate to combat these pressures (Basher and Sadorsky, 2016). Since both the inflation rate and interest rate, which constitute the discount rate, are influenced by oil price, it follows that the rise in oil price raises the discount rate, and thus, reduces the stock returns.

In fact, the response of aggregate stock returns to oil price changes greatly depends on whether the country in question is an oil importing or exporting country. For a net importer of oil, a rise in oil price puts a downward pressure on the country's foreign exchange rate and upward pressure on domestic inflation rate. Because a higher expected inflation rate raises the discount rate, an increase in oil prices has a negative impact on stock returns (Huang et al. 1996). A positive impact is, however, expected on stock market in oil exporting countries as a reaction to a change in oil prices. The mechanism can be explained through income and wealth effects. A rise in oil prices raises government revenues, and public expenditure on infrastructure may increase. Furthermore, higher prices lead to an immediate transfer of wealth from net oil importers to net oil exporters. Government spending on purchasing domestic goods and services generates a higher level of economic activity and improves stock market returns in these countries (Bjornland, 2009).

\subsection{Empirical Literature}

A wide range of empirical studies have examined the relationship between oil prices and macroeconomic variables, such as GDP, inflation rate, employment and exchange rate. The pioneer work of Hamilton (1983) on the relationship between oil prices and real GDP in the United States reveals that there is a negative effect of oil price increases on real GDP. This result has been confirmed by a number of other researchers.

A variety of studies have emerged later to examine another relation with oil prices, specifically, the nexus between oil prices and stock market returns. The paper of Jones and Kaul (1996) was among the first studies to analyse the response of international stock markets of four developed countries, namely; the United States, Canada, Japan and the UK to changes in oil price. Using simple regression models, they find that oil prices have a negative effect on stock returns for all these countries. Sadorsky (1999) in his study for the USA has reached to the same conclusion. Park and Ratti (2008) have used the VAR technique for the period 1986:01 - 2005:12 to examine the impact of oil price on stock returns in the US and a group of thirteen European oil Importing and exporting countries. Empirical evidence shows that the stock market response to oil changes has been as follows: For oil exporting countries; a significantly positive reaction in Norway, insignificant effect in the UK, a significant negative impact in Denmark. While for oil importing countries the effect has been significantly negative.

Research on the oil price-stock returns link has been developed to include analysis of the asymmetric effect of oil price shocks, as well as oil price volatility. Arouri and Fouquau (2009) in their study for GCC stock markets have investigated the long run relationship between oil prices and stock market, as well as the asymmetry aspect of oil price shocks. The findings of the study provide evidence that oil price stocks affect the stock returns in an asymmetric manner. Stock market prices rise faster than they fall as a response to changes in oil prices. This result has been supported by the study of Moghadam (2010), who has examined asymmetric impact of oil price shocks on stock returns on the basis of a multivariate GARCH approach. A different method has been applied in a recent study conducted by Zhu et al. (2016) for China. They have used a quantile impulse response approach to examine the impact of oil price shocks on Chinese stock returns. The results suggest this relation presents asymmetric features. During a boom phase, the aggregate demand shock enforces stock returns, while during a bust period oil supply and demand shocks depress significantly stock returns. 
On the volatility aspect of the oil price - stock returns nexus Dhaoui and Khraief (2014) investigate the effect of oil price shocks on stock market returns for eight developed countries over the period 1991-2013. The findings of the study indicate that there exists a strong negative relation in all countries under consideration except Singapore. On the volatility side, the changes in oil prices are significant for six markets. The results of a more recent study for developed countries also (the G-7countries) carried out by Diaz and Gracia (2016) confirm the negative reaction of the G-7 stock markets to an increase in oil price volatility. Regarding emerging economies, the study of Masih and Mello (2010), for South Korea represents a good example on volatility of oil prices. It investigates the impact of oil price fluctuations and oil price volatility on equity stock market returns, using a vector error correction model which includes interest rates, economic activity, real stock returns, real oil prices and oil prices volatility. Evidence shows the dominance of oil price volatility on real stock returns and that it increases over time.

The study of Ramos, Sofia and Velga, Helena (2010) is of particular importance, because it considers both developed and emerging economies (43 stock markets), and it analyzes several aspects of the oil price-stock returns relationship; cointegration, asymmetry and volatility. Results concerning developed countries indicate that increases in oil prices depress international stock markets, while decreases in oil prices do not necessarily increases stock market returns. In addition, the volatility of oil prices has a negative effect on international stock market returns. Comparison with the results of emerging market returns, they are not sensitive to oil price variations. Moreover, the asymmetry of oil price changes impacts oil volatility also, so that, when oil prices increases, oil volatility increases, while negative oil price changes dampen volatility.

As far as Jordan is concerned, it seems that the researchers investigating the relationships among oil prices, stock market returns and macroeconomic variables are not so much interested in exploring the oil-macroeconomics relation, or oil-stock returns nexus. Most of them have focused on examining the effect of macroeconomic variables, such as: interest rate, inflation rate and gross domestic product, on stock returns. Examples of these studies are: Al-Sharkas (2004), Momani, and Alsharari (2012), and Al-Majali and Al-Assaf (2014).

On the specific relationship between oil prices and stock returns, studies for Jordan are scarce. Al-Qudah (2014) has conducted a research to examine the cointegration and causality between oil price shocks and short-term interest rate and Amman stock exchange real returns, using monthly data for 2000:01 - 2014:06 period. The methodology applied consists of co integration test, VAR, impulse response function and variance decomposition function, in addition to Granger causality test. The impulse response shows that a shock of oil prices has a significant negative effect on Amman stock exchange real returns almost after two months. The author further finds that there is a unidirectional causality running from oil price shocks and short-term interest rate to stock real returns.

However, Jordan's case has been studied in some articles that cover several countries. Al-Fayoumi (2009) in his research on three oil - importing countries: Turkey, Tunisia, and Jordan has investigated the impact of oil prices, interest rate and industrial production index on stock returns. Application of the error correction model over the 1997-2008 period reveals an insignificant effect of oil price changes on stock market returns in the three countries, while the local macroeconomic variables are more important than that of oil. Comparison of the results of this study on oil-importing countries to those of Arouri and Julien (2009) for the GCC countries (oil exporters) provides different findings, and hence, indicates that research distinguishing between oil-importing countries, such as Jordan, and those exporting oil is necessary.

Moreover, Al-Fayoumi's (2009) study has covered a period of time before the financial crises. The results however, may differ if the crises impact has been considered. Indeed, the study of Ajmi et al. (2014) covering eleven Middle East and North Africa (MENA) countries including Jordan, for the period during and after the financial crisis (2007-2012) has provided different conclusions. They find strong evidence supporting the asymmetry hypothesis, that the signs of changes in oil prices are significant for detecting the true causality links. Most MENA stock markets have been influenced by the signs of oil price changes, but differently. The Saudi Arabian stock market reveals nonlinear sensitivity to both positive and negative changes in the oil prices. Non-oil producers, such as Jordan and Morocco, react differently to these changes; in Jordan, positive changes in oil prices affect the stock market returns, while negative changes cause stock returns movements in Morocco.

In the study of Gomes and Chaibi (2014), the volatility transmission mechanism across frontier markets (21 stock markets including that of Jordan) has been analyzed. A bivariate BEKK-GARCH $(1,1)$ model has been employed using data for the period of 2008-2013. The results suggest significant transmission of shocks and volatility between oil prices and some of the examined markets. The authors further find that the second highest coefficient measuring the volatility spillover from oil to stock market is that of Jordan, following Qatar, Nigeria and the United Arab Emirates. 
Another extension of the oil price-stock market nexus is the sectoral relations. Dogan et al. (2016) have examined Jordan's case among the MENA countries. The data consist of a balanced panel of 481 firms during June 2005 June 2015. The findings of the study shows that oil prices affect real stock returns positively for MENA countries, particularly for small firms and those in manufacturing, services, and wholesale and retail industries.

Based on the above review of relevant literature, considering that for Jordan, the results of investigating the impact of oil price changes on stock returns are mixed, due to disparities in the methodology used, period of the study, specification of the econometric model and the conditions of the countries examined. Hence, focusing on a specific study that analysis Jordan case, as an oil-importing country and considering longer period of time, in addition to employing recent developed econometric methods represents a significant motivation for us to conduct this research. We hope that this study adds to the existing literature on this important area of research.

\section{Methodology}

Classical cointegration analysis assumes a symmetric adjustment process in the relationship among variables, however, many economic variables show asymmetric adjustment paths, including oil prices and stock market indicators. As a result, losing the power of a classical cointegration tests such as Engle-Granger Two Step procedure and Johansen approach to detect the long-run equilibrium relationship is possible. Based on their analysis, it is assumed that the adjustment mechanism of the error correction term (ECT) is symmetric, which means that the adjustment coefficients to the equilibrium level are the same for both positive and negative values of the residual obtained from the long-run relationship. This indicates that the speed of adjustment of the stock market returns, used in our analysis, is the same no matter if the shocks to oil prices are positive or negative, (see Al-Assaf 2014).

These tests were modified by including an asymmetric error correction term to investigate the cointegration relationships of the asymmetric adjustment by Enders and Granger (1998). In their paper, the development of the threshold and momentum threshold model was achieved by starting with the long-run cointegrating regression as follows:

$$
S M R_{t}=\beta_{0}+\beta_{1} O P_{t}+\beta_{i, 2} X_{i t}+u_{t}
$$

Where $S M R$ represents stock market returns at time $(t)$,

OP: fluctuations in oil prices at time $(t)$, and the Crude Oil Brent Price (dollar per barrel) is used for the oil price variable.

$\mathrm{X}$ : represents other explanatory variables used in the literature that might affect stock market returns, and that include real GDP (LRGDP), interest rate expressed by discount rate (DR).

All variables are expressed in logarithms except variables expressed in ratio.

$u_{t}$ : is the error term.

If the variables are integrated of the same order, the first step then is to obtain the error term from the previous equation $\left(\hat{u}_{t}\right)$ and test it for stationarity. In order to detect a potential cointegration relationship this error has to be $\mathrm{I}(0)$. The augmented Dickey-Fuller (ADF) statistic can be used to ascertain whether the residuals, $\hat{u}_{t}$, are stationary. The Engle-Granger Framework for cointegration was generalized by Balke and Fomby (1997) to allow for nonlinear adjustment by partitioning the lagged residuals from the cointegration regression using a Heaviside indicator function $\left(\mathrm{I}_{\mathrm{t}}\right.$ ) which is basically based on the threshold idea of Tong (1983). Two popular threshold cointegration tests are usually employed to detect asymmetric cointegration relationship among set of variables. These are called the TAR and MTAR tests. The basic form of these two test allow for only one threshold, hence two regimes, and can be presented in equation (2) for the error term, where the null hypothesis for both tests indicating no cointegration with asymmetry $\left(\rho_{1}=\rho_{2}=0\right)$.

Where

$$
\Delta \hat{u}_{t}=\rho_{1} I_{t} \hat{u}_{t-1}+\rho_{2}\left(1-I_{t}\right) \hat{u}_{t-1}+\epsilon_{t}
$$

$\hat{u}_{t}$ are the residuals from the cointegrating regression

$I_{t}$ is the Heaviside indicator function:

$$
\text { TAR: } I_{t}=\left\{\begin{array}{lll}
1 & \text { if } & q_{t-1} \geq \tau \\
0 & \text { if } & q_{t-1}<\tau
\end{array}\right.
$$

$$
\text { MTAR: } I_{t}= \begin{cases}1 & \text { if } \Delta q_{t-1} \geq \tau \\ 0 & \text { if } \Delta q_{t-1}<\tau\end{cases}
$$

$\tau$ : is threshold location

$q_{t-1}$ is the threshold indicator variable 
It is clearly seen that the only difference between the TAR specification and the MTAR specification is the definition of the Heaviside indicator function $\left(\mathrm{I}_{t}\right)$; the Heaviside indicator function is based on the level of value of the threshold indicator variable in the former and the change in the threshold indicator variable in the later.

Enders and Siklos (2001) suggest two sequential steps of testing for threshold cointegration: the first one is to test for the linear cointegration and the second one is to test for the nonlinear adjustment process. The first step is the linear cointegration test which is to test the null hypothesis of using the F statistics. Because of the fact that F statistic is non-standard under the null hypothesis of no cointegration against the alternative of cointegration with asymmetry, where the null of $\rho_{1}=\rho_{2}=0$ is examined using an F-test of the joint hypothesis. The corresponding critical values are obtained from a simulation and are found in Enders and Siklos (2001). However, in the first test (TAR), the value of $\tau$ is set equal to 0 , and in the second test (M-TAR), $\tau$ is unknown. The F statistic is denoted by $\Phi$ and $\Phi^{*}$, for the TAR and M-TAR models, respectively. If this statistic rejects the null of no cointegration, we then implement the second step of testing for the null hypothesis of whether there is symmetric adjustment, that is $\rho_{1}=\rho_{2}$ with the standard F statistic.

Once the asymmetric cointegration relationship among variables is detected, the next step is to formulate the asymmetric error correction model by including the error in the following ECM representation,

$$
\Delta S M R_{t}=\alpha \hat{u}_{t-1}+\sum_{i=1}^{p} \lambda_{i} \Delta S M R_{t-i}+\sum_{i=1}^{p} \gamma_{i} \Delta O P_{t-i}+\sum_{i=1}^{p} \delta_{i} \Delta X_{i t-i}+\eta_{t}
$$

Where $\Delta$ indicating the first difference operator, and $\mathrm{p}$ the lag-length. The term $\hat{u}_{t-1}$ is the error correction term obtained from the cointegrating regression in (1), and $\alpha$ represents the speed of adjustment to the equilibrium. Granger and Lee (1989) extended the ECM specification presented in equation (3) to the case of asymmetric adjustment. Allowing for asymmetries requires that residuals and first differences of explanatory variables can be decomposed into positive and negative values. This can be represented in equation (4) as follows:

$$
\begin{gathered}
\Delta S M R_{t}=\alpha^{+} \hat{u}^{+}{ }_{t-1}+\alpha^{-} \hat{u}^{-}{ }_{t-1}+\sum_{i=1}^{p} \lambda_{i}^{+} \Delta S M R_{t-i}^{+}+\sum_{i=1}^{p} \lambda_{i}^{-} \Delta S M R_{t-i}^{-}+\sum_{i=1}^{p} \gamma_{i}^{+} \Delta O P_{t-i}^{+}+ \\
\sum_{i=1}^{p} \gamma_{i}^{-} \Delta O P_{t-i}^{-}+\sum_{i=1}^{p} \delta_{i}^{+} \Delta X_{i t-i}^{+}+\sum_{i=1}^{p} \delta_{i}^{-} \Delta X_{i t-i}^{-}+\eta_{t}
\end{gathered}
$$

Detecting asymmetry in the speed of adjustment can introduced by defining $\hat{u}^{+}{ }_{t}$ equal to $\hat{u}_{t}$ if $\hat{u}_{t}>0$ and to zero if $\hat{u}_{t} \leq 0$, while $\hat{u}^{-}{ }_{t}$ equals to $\hat{u}_{t}$ or zero when $\hat{u}_{t}<0$ or $\hat{u}_{t} \geq 0$. Similarly, short-run asymmetry is captured by decomposing the first differences into positive and negative components. Having statistically significant for the estimated coefficients in the previous equation indicating the presence of asymmetric pattern in the relationship between stock market returns and oil prices. However, in order to establish if the estimated coefficients of model (4) are statistically different, the single and joint hypotheses $H_{0}: \alpha^{+}=\alpha^{-}, \lambda_{i}^{+}=\lambda_{i}^{-}, \gamma_{i}^{+}=\gamma_{i}^{-}, \delta_{i}^{+}=\delta_{i}^{-}$have to be formally tested. The asymmetric ECM has often been used as an appropriate framework for conventional $\mathrm{F}$ tests of both the hypothesis of symmetric adjustment to the long-run equilibrium and the hypothesis of short-run symmetry. A few previous studies have shown that standard tests of symmetry are affected by low power in an ECM framework. The optimal solution here is to bootstrap the calculated $\mathrm{F}$ statistic and obtain the corresponding rejection frequencies via simulation (see Cook 2007, and Galeotti et al. 2003).

\section{Empirical Results}

The pre-requisite step is to test for a unit root to examine the order of integration. Table 1 shows the results of unit root tests obtained using the ADF test. These results reveal the null hypothesis, the series contains a unit root, should not be rejected in favour of the alternative hypothesis at one, five and ten percent levels of significance. This confirms that our series are integrated of the same order, and they are I(1). 
Table 1. Augmented Dicky-Fuller Unit Root Test

\begin{tabular}{cccccc}
\hline \multicolumn{5}{c}{ Null Hypothesis: Variable is non-stationary } \\
\cline { 2 - 5 } Variables & \multicolumn{2}{c}{ Level } & \multicolumn{2}{c}{ First Difference } & Conclusion \\
\cline { 2 - 5 } & $\mathrm{C}$ & $\mathrm{C}+\mathrm{T}$ & $\mathrm{C}$ & $\mathrm{C}+\mathrm{T}$ & \\
\hline LSMR & -1.73 & -2.04 & $-8.42 *$ & $-8.73 *$ & $\mathrm{I}(1)$ \\
\hline LOP & -1.46 & -0.70 & $-6.50 *$ & $-6.67 *$ & $\mathrm{I}(1)$ \\
\hline LRGDP & -1.85 & -0.67 & $-2.63 * * *$ & $-3.11 * * *$ & $\mathrm{I}(1)$ \\
\hline DR & -2.44 & -2.47 & $-3.22 * *$ & $-3.77 * * *$ & $\mathrm{I}(1)$ \\
\hline
\end{tabular}

- *(**), and $* * *$ denote reject at $1 \%(5 \%)$, and 10\%, respectively for tests with constant $(\mathrm{C})$ and constant and trend $(\mathrm{C}+\mathrm{T})$.

It is important first to establish the cointegrating regression wish represents the long-run relationship among variables under estimation. The empirical results of this estimation are presented in Table 1 . The error $\left(\hat{u}_{t}\right)$ is then obtained from this regression and used to test for cointegration.

Table 2. Cointegrating Regression

\begin{tabular}{|c|c|c|}
\hline \multicolumn{3}{|c|}{$\begin{array}{l}\text { Dependent Var. SMR } \\
\text { No. of Obs. } 64 \\
\text { Period of Time: } 2000 \text { Q1-2015Q4 }\end{array}$} \\
\hline Independent Var. & Coefficient & Std. Error \\
\hline OP & $-0.0034 * * *$ & 0.0019 \\
\hline LRGDP & $0.0098 * *$ & 0.0042 \\
\hline DR & $-0.0017^{*}$ & 0.0005 \\
\hline Constant & $0.0714^{*}$ & 0.0255 \\
\hline
\end{tabular}

$*(* *) * * *$ indicate significant at $1 \%(5 \%)$ and $10 \%$ respectively.

Firstly, the results of Engle-Granger test for cointegration show that there is a potential cointegration relationship between stock market returns and other variables including oil prices (see Table 3). However, we are interested in this paper to examine whether this cointegration relationship is with asymmetry patterns or not. In order to do this, we decompose the error obtained from equation (1) into a positive and negative values and then conducting the test of Enders Siklos for both TAR and MTAR models. The test is conducted by using both F-statistic and t-Max. It is found that there is an evidence for an asymmetric cointegration between oil prices and stock market returns as shown in Table (3) since the $\Phi$ statistic for the null hypothesis is 2.63 which in greater than the $1 \%$ and $5 \%$ critical values and we therefore can reject the null hypothesis of no asymmetric cointegration at $1 \%$ and $5 \%$ level of significance, whereas the largest of t-statistics equals -3.039 rejects the null hypothesis at all significance levels.

Table 3. Engle-Granger Cointegrating Test

\begin{tabular}{cccc}
$H_{0}: u_{t}$ has a unit root & \multicolumn{3}{c}{ Critical Values } \\
\hline t-statistic & $1 \%$ & $5 \%$ & $10 \%$ \\
\hline$-8.116^{*}$ & -3.540 & -2.909 & -2.592 \\
\hline
\end{tabular}

*(**) indicate significant at $1 \%$ and $(5 \%)$ respectively. 
The previous Engle-Granger test shows a cointegration test among oil prices and stock market returns. To allow for the possibility of nonlinearity in the cointegration relationship found using this test, we apply the Enders-Siklos test. However, using this test can enable us to re-examine the cointegration relationship between oil prices and stock market returns in both TAR and MTAR models, and the empirical results are reported in Table 4 . The $\Phi^{*}$ statistic indicates that we can reject the null hypothesis of no cointegration with asymmetry. This implies that asymmetric adjustment between oil prices and stock market returns is confirmed since the F-statistic indicates that the null hypothesis is rejected at 5\% level (which assume symmetric adjustment $\rho_{1}=\rho_{2}$ ). This verifies that there exists a long-run cointegration relationship among oil prices and stock market returns in Jordan with underlying adjustment process being highly asymmetric.

Table 4. Enders-Siklos Asymmetric Cointegration Tests

\begin{tabular}{ccccccc}
\hline \multirow{2}{*}{ Variables } & \multicolumn{3}{c}{$H_{0}: \rho_{1}=\rho_{2}=0$} & \multicolumn{2}{c}{$H_{0}: \rho_{1}=\rho_{2}$} \\
\cline { 2 - 7 } & TAR: $\Phi^{*}$ & $k$ & MTAR: $\Phi^{*}$ & $k$ & TAR: F-statistic & MTAR: F-statistic \\
\hline SMR, OP, & $7.21^{* *}$ & 2 & 3.41 & 3 & $6.86^{* *}$ & 1.27 \\
RGDP, DR & & & & & &
\end{tabular}

$*(* *)^{* * *}$ indicate significant at $1 \%(5 \%)$ and $10 \%$, respectively. The notation $\mathrm{k}$ is the lagged difference term, which is selected based on the AIC. The critical values of $\Phi$ and $\Phi^{*}$ statistics are given by Enders and Siklos (2001). F statistic is used for the null hypothesis if symmetric adjustment, $\rho_{1}=\rho_{2}$.

As we detect a cointegration relationship with asymmetric patterns between variables, we can then proceed to estimate the asymmetric ECM in order to explore the symmetric adjustment process in our model. The adjustment coefficients presented in Table 5 show that since the asymmetric adjustment coefficient is larger (1.14), when it is positive than negative, rising in oil prices, will have a bigger impact on stock market returns (Note 1). This also confirms the facts that increase in oil prices play a very significant impact on the behaviour of stock market in Jordan. Noting that estimated model is free of problems of non-normality, autocorrelation, ARCH effects and heteroskedasticity and other diagnostic tests (the results of these test are not shown here).

Table 5. The Asymmetric ECM Estimates

\begin{tabular}{ccc}
\hline Variables & \multicolumn{2}{c}{ Adjustment Coefficients } \\
\cline { 2 - 3 } & $\alpha^{+}$ & $\alpha^{-}$ \\
\hline SMR, OP, GDP, DR & $-1.140^{*}$ & $0.52^{* * *}$ \\
& $(0.159)$ & $(0.291)$
\end{tabular}

$*(* *)^{* * *}$ indicate significant at $1 \%(5 \%)$ and $10 \%$, respectively. Standard errors are in parentheses.

\section{Conclusion}

In this article we attempt to deepen our understanding of the oil price-stock returns association through testing the asymmetric cointegration relationship between these two variables, particularly, as the last two decades have witnessed several considerable fluctuations in crude oil prices.

Jordan, which is a net oil-importing country, is heavily dependent on oil to meet its energy requirements for the various activities. Hence, Jordanian stock market is likely to be sensitive to oil price variations. This feature has stimulated us to empirically examine whether Amman stock market responds in an asymmetric pattern to different variations (positive or negative) in crude oil prices, focusing on oil price-stock returns nexus in both the long run and short run, and considering both the linear and nonlinear frameworks.

Based on the TAR and MTAR specification of Enders and Siklos's (2001) model, and using asymmetric ECM, we reached to the conclusion that there exists asymmetry in the adjustment process to equilibrium. In particular, we observed a greater impact on stock returns when oil prices increase than the decrease had. 
These findings could be useful for researchers, planners and different stock markets participants. For investors, the significant relationship between oil prices and stock returns strengthen their predictability power, so that appropriate strategies may be built on the basis of expected increases or decreases in oil prices. Researchers, however, can further contribute to the literature by providing thorough explanation for the causes of the asymmetry's basion reaction of stock returns to oil prices changes. Moreover, other aspects of this relation may be emphasized and investigated in detail, such as the asymmetry according to subsectors of the industrial activity.

\section{References}

Ajmi, Ahdi, Montasser, Gassan, Hammoudeh, Shawkat, \& Nguyen, Duc. (2014). Oil prices and MENA stock markets: New evidence from nonlinear and asymmetric causalities during and after the crisis period. Working Paper Series, IPAG Business School.

Al-Assaf, G. (2014). Testing for asymmetric cointegration relationship between banking sector development and trade openness: Evidence from Jordan. Dirasat: Administrative Sciences, 41(2).

Al-Fayoumi, A.N. (2009). Oil prices and stock market returns in oil importing countries: The case of Turkey, Tunisia and Jordan. European Journal of Economics, Finance and Administrative sciences, 16, 86-101.

Al-Majali, Ahmad, \& Al-Assaf Ghazi. (2014). Long-run and short-run relationship between stock market index and main macroeconomic variables performance in Jordan. European Scientific Journal, 10(10), 156-171.

Al-Qudah, Ali. (2014). The impact of oil price shocks on Amman stock exchange real returns. International Journal of Business and Social Science, 5(12), 224-235

Al-Sharkas, Adel. (2004). The dynamic relationship between macroeconomic factors and the Jordanian stock market. International Journal of Applied Econometric and Quantitative Studies, 1(1), 97-114.

Arouri, Mohamed, \& Fouquau, Julien. (2009). How do oil prices affect stock returns in GCC markets? An asymmetric cointegration approach. Retrieved from http://www.aaee.at/2009-IAEE/index.php

Balke, N.S., \& Fomby, T.B. (1997). Threshold cointegration. International economic review, 627-645.

Basher, S.A., \& Sadorsky, P. (2006). Oil price risk and emerging stock markets. Global Finance Journal, 17(2), 224-251.

BP Statistical Review of World Energy. (2016). Retrieved from https://www.bp.com/content/dam/bp/pdf/energy

Cook, S. (2007). A Threshold Cointegration Test with Increased Power. Mathematics and Computers in Simulation, 73(6), 386 - 392.

Dhaoui, Abderrazak, \& Khraief, Naceur. (2014). Empirical linkage between oil price and stock market returns and volatility: Evidence from international developed markets. Economics, 20(2).

Diaz, Elena, Molero, Juan, \& Gracia, Femando. (2016). Oil price volatility and stock returns in the G7 Economics. Energy Economics, 54(4), 417-430.

Dogan, F., Silahli, Baykar, Cifter, Atilla, \& Akay, Gokhan. (2016). The effects of oil prices on stock returns in MENA countries: A firm-level date analysis. Retrieved from http://www.dohainstitute.edu.qa/MEEA2016/downloads/fadime\%20dogan_Final.pdf

Galeotti, M., Lanza, A., \& Manera, M. (2003). Rockets and feathers revisited: an international comparison on European gasoline markets. Energy Economics, 25, 175-190.

Gomes, Mathieu, \& Chaibi, Anissa. (2014). Volatility spillovers between oil prices and stock returns: A focus on frontier market. The Journal of applied Business Research, 30(2), 509-526.

Granger, C.W.J., \& Lee, T.-H. (1989). Investigation of production, sales and inventory relationships using multicointegration and non-symmetric error correction models. Journal of applied econometrics, 4(S1), S145-S159.

Hamilton, D.J. (1983). Oil and the macroeconomy since World War II. The Journal of Political Economy, 9, 228-248.

Haung, D.R., Masulis, R.W., \& Stoll, H. (1996). Energy shocks and financial markets. Journal of Future Markets, $16(1), 1-27$

Jones, M.C., \& Kaul, G. (1996). Oil and stock markets. Journal of Finance, 51(2), 463-491.

Masih, Rumi, Perters, Sanjay, \& Mello, Lurion. (2010). Oil price volatility and stock price fluctuations in an 
emerging market: Evidence from South Korea. Energy Economics, 33(5), 975-986.

Moghadam, Hamed. (2010). Asymmetric effect of oil price shocks on stock markets. Retrieved from http://www.ssm.com/abstract=2787019

Momani, Gazi, \& Alsharari, Majed. (2012). Impact of economic factors on the stock prices at Amman stock market (1992 - 2010). International Journal of Economics and Finance, 4(1), 151-159.

Park, J., \& Ratti, R.A. (2008). Oil price and stock markets in the U.S. and 13 European countries. Energy Economics, 30, 2587-2608.

Ramos, Sofia, \& Velga, Helena. (2010). Asymmetric effects of oil price fluctuations in international stock markets. Working papers. Universidad Carlos III de Madrid.

Sadorsky, P. (1999). Oil price shocks and stock market activity. Energy Economics, 21, 449-469.

Tong, H. (1983). Threshold models in non-linear time series analysis. Springer-Verlag New York.

Zhu, H., Su, X., Guo, Y., \& Ren, Y. (2016). The asymmetric effects of oil price shocks on the Chinese stock market: Evidence from a quantive impulse perponse perspective. Sustainability, 8(766), 1-19.

\section{Note}

Note 1. The full empirical results of the asymmetric ECM (short-run asymmetric coefficients) are presented in Table A1 in the appendix of this paper.

\section{Appendix}

Table A1. The Full Asymmetric ECM Estimates

\begin{tabular}{lcc}
$\begin{array}{l}\text { Dependent Var. } \Delta S M R_{t} \\
\text { No. of Obs. } 61 \\
\text { Period of Time: 2000Q1-2015Q4 }\end{array}$ & \\
\hline $\begin{array}{c}\text { Independent Var. } \\
\hat{u}^{+}{ }_{t-1}\end{array}$ & Coefficient & \\
\hline$\hat{u}_{t-1}^{-}$ & $-1.140^{*}$ & Std. Error \\
\hline$\Delta S M R_{t-1}^{+}$ & $0.52^{* * *}$ & 0.159 \\
\hline$\Delta S M R_{t-2}^{+}$ & $-1.393^{*}$ & 0.291 \\
\hline$\Delta S M R_{t-1}^{-}$ & 0.885 & 0.638 \\
\hline$\Delta S M R_{t-2}^{-}$ & 1.181 & 0.592 \\
\hline$\Delta O P_{t-1}^{+}$ & $0.085^{* * *}$ & 0.624 \\
\hline$\Delta O P_{t-2}^{+}$ & 0.009 & 0.162 \\
\hline$\Delta O P_{t-1}^{-}$ & $-0.016^{* * *}$ & 0.011 \\
\hline$\Delta O P_{t-2}^{-}$ & 0.001 & 0.009 \\
\hline$\Delta R G D P_{t-1}^{+}$ & $-0.019^{*}$ & 0.006 \\
\hline$\Delta R G D P_{t-2}^{+}$ & $0.053^{* * *}$ & 0.007 \\
\hline$\Delta R G D P_{t-1}^{-}$ & $0.038^{* * *}$ & 0.028 \\
\hline$\Delta R G D P_{t-2}^{-}$ & $0.049^{* * *}$ & 0.026 \\
\hline$\Delta D R_{t-1}^{+}$ & -0.026 & 0.026 \\
\hline$\Delta D R_{t-2}^{+}$ & 0.001 & 0.044 \\
\hline$\Delta D r_{t-1}^{-}$ & $-0.004^{*}$ & 0.003 \\
\hline$\Delta D R_{t-2}^{-}$ & 0.002 & 0.001 \\
\hline & $0.006^{* *}$ & 0.003 \\
\hline
\end{tabular}

$*(* *)^{* * *}$ indicate significant at $1 \%(5 \%)$ and $10 \%$, respectively. 